\title{
Learning to teach
}

\section{Can studies of how people learn be put to use in the classroom?}

\section{Original Intelligence: Unlocking the Mystery of Who We Are \\ by David \& Ann Premack \\ McGraw-Hill: 2003. 274 pp. $\$ 24.95$}

\section{Peter Bryant}

Cognitive scientists study the nature of intelligence, and therefore of learning, and several of them have in recent years turned their attention to children's education. The reason is simple and impeccable: they have made discoveries about how people acquire knowledge that should be of value to schoolteachers in helping children learn new things. This is the approach taken by David and Ann Premack in this highly impressive book on intelligence and education.

The Premacks start their book with an account of the basic mechanisms of learning, and end it with a set of specific suggestions for ways of teaching children in schools. In between they set out their conclusions about their own research and that of others on topics of central importance in cognitive psychology, including language, mathematics, memory, causal reasoning and reasoning through analogy.

In their opening remarks on learning, the Premacks argue strongly for the existence and importance of modules - highly specialized mechanisms for acquiring different forms of knowledge. According to modular theories, children largely depend on modules for learning to speak (the language module), for finding out how to count, add and subtract (the number module), and for acquiring everyday biological and physical knowledge (the biological and physical modules). The Premacks also review some of the physiological support for the idea of separate mechanisms for learning. Modular theories, it should be said, resonate well with the geographical approach that has dominated cognitive neuroscience for several decades now - the idea that this bit of the brain underlies our spatial knowledge, another bit over there subserves language, and right at the front somewhere you will find the regions responsible for planning, say, and perhaps theory of mind.

The chapters that follow deal with topics such as analogy, and causal and social reasoning, which are at the centre of the Premacks' justly famous research using chimpanzees and, later on, young children. The ingenuity and originality of these experiments are truly astonishing, and the authors' account of the work is clear and exciting. It is also impressive to see how many new ideas the Premacks come up with in these chapters. They challenge, for instance, the traditional idea that

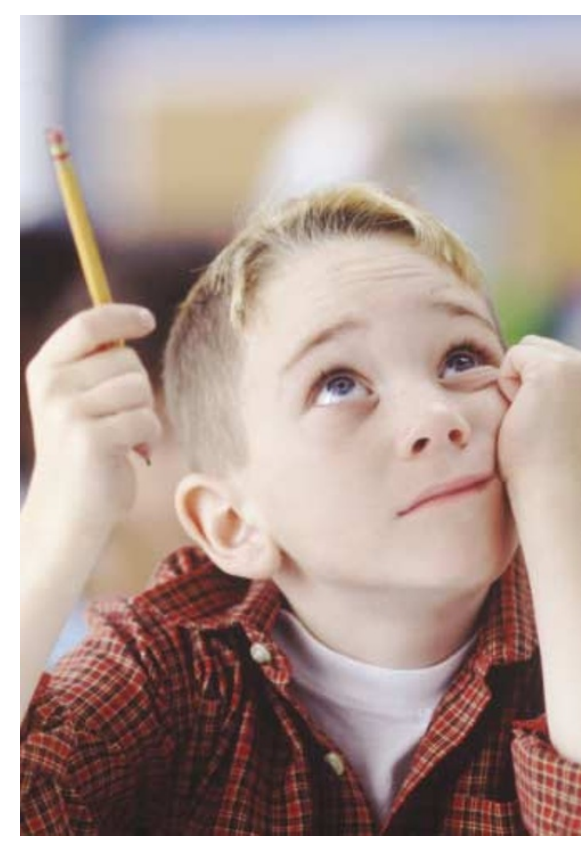

Waiting for the penny to drop: cognitive science may be able to help children learn.

belief is an intervening variable. It is often held that people build up beliefs through experience and inferences, and then act on these beliefs. But on the basis mainly of work with young children, the Premacks argue instead for a direct route between our perceptions and inferences and what we do.

The ideas in the chapter on the theory of mind are also strikingly original. This topic is about our ability to work out what is in another person's mind. The Premacks introduced this hugely important issue into cognitive psychology in the 1970s, and it would have been easy for them to spend this part of the book resting on their well-deserved laurels. Instead, they quite rightly criticize the way in which success in 'false belief' tasks has become the modern gold standard for holding a theory of mind. These tasks test whether a child can understand that someone else can hold an incorrect but quite legitimate belief about an object or a set of events. Even though some of their own initial research on theory of mind involved false beliefs, the Premacks argue here that other criteria and tasks are just as important, and give a stimulating account of some experiments on understanding the intentions of others engaged in goal-directed actions.

Early on in the book there is a chapter on pedagogy, in which the Premacks claim that "the root of human pedagogy lies in aesthetics, in the judgement of beauty which, like charity, begins at home". I find this particular argument hard to follow, and hard to link to their correct assertion in the same chapter that humans need teachers more than other species do because specialization in human intelligence has led to inventions and intellectual advances that we cannot expect successive generations to learn without help. These human achievements, which L. S. Vygotsky called 'cultural tools', have to be taught, and at the end of their book the Premacks turn their attention to how best to do this teaching.

The journey from the psychological laboratory to the school classroom is complicated and hazardous, for these are two very different places. "You make a great, a very great mistake," the psychologist William James once thundered, "if you think that psychology, being the science of the mind's laws, is something from which you can deduce definite programmes and schemes and methods of instruction for immediate schoolroom use." If this is a mistake, then I am afraid that the Premacks seem to have made it. They outline educational programmes but provide no evidence that they actually work. Such research is difficult to do-difficult, but essential.

The Premacks also ignore a large amount of existing research, both psychological and educational, on how to help children make the advances that they themselves wish to encourage. For instance, their claim that "the basic idea of a fraction can be taught by dividing an object into a number of parts" actually describes a fairly widespread classroom practice, and sidesteps some excellent research on children's learning about proportions and fractions that certainly deserves a mention. The Premacks' assertion that children learning to read will come to segment words into various phonological units by seeing their own speech transformed into print is interesting and worth a try. However, a great deal of quite sophisticated work on children's awareness of phonology suggests that it won't work.

Why wasn't any of this work mentioned in this book? I think the reason is that the Premacks' main educational idea is that one ought to give modules, which are innate learning mechanisms, a chance to learn. The twists and turns of research into children's developing understanding of proportions, phonology or physics do not fit the Premacks' bill, which is a pity because not all of this research is bad. This educational chapter provides an interesting but downbeat ending to a provocative and valuable book.

Peter Bryant is in the Department of Experimental Psychology, University of Oxford, South Parks Road, Oxford OX1 3UD, UK. 